\title{
Xanthine oxidase and uric acid in atrial fibrillation
}

\author{
Panagiotis Korantzopoulos ${ }^{1}$, Konstantinos P. Letsas ${ }^{2}$ and Tong Liu ${ }^{3}$ \\ 'Department of Cardiology, University of loannina Medical School, loannina, Greece \\ ${ }^{2}$ Second Department of Cardiology, Evangelismos General Hospital, Athens, Greece \\ ${ }^{3}$ Department of Cardiology, Tianjin Institute of Cardiology, Second Hospital of Tianjin Medical University, Tianjin, People's Republic of China \\ *Correspondence: p.korantzopoulos@yahoo.gr
}

\section{BACKGROUND}

The pathophysiology of atrial remodeling is very complex and the molecular pathways implicated in the initiation and perpetuation of atrial fibrillation (AF) show a high diversity and variability across different underlying substrates (Schotten et al., 2011; Wakili et al., 2011). During the past few years the role of pathophysiologic pathways that involve inflammatory and oxidative processes is under meticulous investigation (Korantzopoulos et al., 2007; Van Wagoner, 2008; Negi et al., 2010). Given that most of the published data on this subject regards the study of inflammatory and oxidative stress markers, the cause-effect relationship with atrial remodeling is not very clear. Possibly, both procedures are operative in this setting. Bearing in mind that most of the associated cardiovascular conditions are associated with oxidative stress and inflammation, the study of oxidative, and inflammatory aspects of atrial remodeling becomes more complicated.

\section{XANTHINE OXIDASE AND URIC ACID IN CARDIOVASCULAR DISEASE}

Accumulating evidence suggests that xanthine oxidase $(\mathrm{XO})$ is an important source of reactive oxygen species (ROS) in cardiovascular disease (Doehner and Landmesser, 2011). In specific, uric acid (UA) derives from the conversion of hypoxanthine to xanthine and of xanthine to UA, both reactions being catalyzed by the enzyme XO (Glantzounis et al., 2005). Ischemia and cellular damage promote xanthine accumulation creating a substrate for $\mathrm{XO}$. This enzyme uses molecular oxygen as electron acceptor and leads to formation of the free radical superoxide anion, thereby promoting oxidative stress (Glantzounis et al., 2005). Superoxide anion can form hydrogen peroxide through superoxide dismutase activity and, in the presence of iron, the extremely reactive hydroxyl radical by Fenton-type reactions. Also, superoxide anion interacts with nitric oxide (NO) forming the toxic molecule peroxynitrite. Collectively, ROS such as hydroxyl radicals and peroxynitrite trigger cellular responses ranging from subtle changes of cell functioning to severe oxidative damage of the affected macromolecules leading to necrosis or apoptosis (Glantzounis et al., 2005).

The highest activity of $\mathrm{XO}$ is detected in endothelium, intestine, and liver. Endothelial XO plays a crucial role in the vascular oxidative stress. Remarkably, angiotensin II-induced NADPH oxidase activation increases $\mathrm{XO}$ activity indicating that there is a redox sensitive activation of endothelial XO (Landmesser et al., 2007). It has also been suggested that endothelialderived ROS have direct effects on myocardial functional performance (Doehner and Landmesser, 2011).

UA has emerged as a simple and independent marker of morbidity and mortality in a variety of cardiovascular disease states including coronary artery disease and heart failure (Dawson and Walters, 2006; George and Struthers, 2008; Ndrepepa et al., 2012). Regardless of the debate whether it is a predictor or a causative factor, UA has been clearly associated with oxidative stress and inflammation in several pathological conditions (Glantzounis et al., 2005; Doehner and Landmesser, 2011). It has also been proposed that UA reflects the presence of other diseases and cardiovascular risk factors that increase oxidative stress.

In pathophysiological terms, UA reflects upregulated XO activity. Apart from this well-known pathway, UA may have additional effects. Specifically, it appears to be a low potency antioxidant outside the cell (Glantzounis et al., 2005). On the other hand, inside the cell it enhances oxidative stress by activating NADPH oxidase while it activates the renin-angiotensin system (Kelkar et al., 2011). Moreover, UA may represent an endogenous signal of cell injury activating the cellular immune response (Shi et al., 2003). In fact, UA has been associated with a pro-inflammatory state in human subjects and particularly with an increase in inflammatory markers (Ruggiero et al., 2006).

\section{URIC ACID METABOLISM AND ATRIAL REMODELING}

Potential sources and factors implicated in AF-related oxidative stress include NADPH oxidase activation, calcium overloading and mitochondrial damage, angiotensin system activation, $\mathrm{NO}$ synthase uncoupling, $\mathrm{XO}$ activation, altered expression of redoxrelated genes, other genetic factors, aging, obesity, and other associated cardiovascular conditions (Korantzopoulos et al., 2007). The presence and localization of $\mathrm{XO}$ in the human heart has been debated. Earlier studies found no evidence of $\mathrm{XO}$ activity (Grum et al., 1989) while latter studies confirmed the presence of $\mathrm{XO}$ activity in human hearts (MacGowan et al., 1995) and besides its localization in capillary endothelial cells additional localization in vascular smooth muscle cells, macrophages, and mast cells was demonstrated (HellstenWesting, 1993).

In a porcine atrial tachypacing model of AF left atrial XO activity was 4.4 times greater in the paced than in the control group. Superoxide production was reduced by $85 \%$ after administration of oxypurinol (a XO inhibitor; (Dudley et al., 2005). In this model, XO in the atria was less abundant than NADPH oxidase. It is worth noting that in another study no significant effect of oxypurinol on superoxide production was found in human atrial specimens, thus failing to support a role of $\mathrm{XO}$ in oxidative stress associated with human AF (Kim et al., 2005). A potential explanation for this evident discrepancy could be the existence of regional differences since in the porcine model the increased XO activity was apparent in the left atrial appendage (Dudley et al., 2005), whereas in the human study only tissue specimens from right atrial appendage were examined (Kim et al., 2005). Of note, in a similar porcine model, 
it was demonstrated that after 1 week of rapid atrial pacing the detectable $\mathrm{NO}$ was decreased in the left but not in the right atrium, indicating that the oxidative stress was enhanced only in the left atrium (Cai et al., 2002). It can therefore be speculated that the left atrium may be preferentially more sensitive to oxidative stress perhaps due to lower metabolic reserve or increased wall stress (Van Wagoner, 2003).

In patients with right or left heart failure it has been demonstrated that hyperuricemia is related to elevated right or left atrial filling pressures (Hoeper et al., 1999). Also, UA levels have been correlated with more impaired right ventricular systolic function and decreased left atrial work in patients with heart failure (Chrysohoou et al., 2008). It would therefore be speculated that UA metabolism is implicated in atrial remodeling given that increased atrial filling pressures cause structural and electrophysiological abnormalities (mechanoelectrical phenomenon) that facilitate the development and perpetuation of AF. In support of this assumption one small study showed a correlation between UA levels and LA diameter, a conventional marker of atrial structural remodeling (Letsas et al., 2010).

Also, there is a possibility that plasma UA is primarily a product of $\mathrm{XO}$ activity in the endothelium, contributing to atrial remodeling indirectly, as a result of its impact on blood pressure and perhaps by atrial effects of UA.

\section{URIC ACID AS A MARKER OF ATRIAL FIBRILLATION RISK}

An increasing body of evidence evidence suggests that UA may represent a marker of AF risk. The positive association between UA levels and AF has been demonstrated in at least seven studies to date (Table 1). In a small observational study we showed a stepwise increase of UA levels in patients with paroxysmal AF and permanent $\mathrm{AF}$ compared to control subjects while after multivariate analysis, UA was an independent predictor of permanent AF (Letsas et al., 2010). Also, in a retrospective observational study of hospitalized patients over 40 years an independent association between high serum UA levels and AF (paroxysmal or persistent) was evident (Liu et al., 2010). In another small observational study we demonstrated an independent association between increased serum UA levels and
$\mathrm{AF}$ in hypertensive patients without significant comorbidities (Liu et al., 2011). In the ARIC study, a large prospective cohort study, elevated serum UA was associated with a greater risk of AF development during the follow-up (Tamariz et al., 2011). Particularly, this association was evident only among blacks and among women (Tamariz et al., 2011). In the same line, a Japanese hospital-based cohort study indicated an independent association between serum UA and AF in women but not in men (Suzuki et al., 2012). We have also shown that UA is an independent predictor of AF recurrence after AF ablation (Letsas et al., 2011). Another very recent study showed that UA levels $\geq 8 \mathrm{mg} / \mathrm{dl}$ was an independent predictor of AF while UA increased significantly between the last year and the year of the first AF detection suggesting a possible involvement in AF development (Kuwabara et al., 2012). Collectively, the aforementioned studies indicate that UA represents a marker of $\mathrm{AF}$ development and perpetuation but the cause-effect relationship is not clear (Watanabe, 2012). Also, the mechanisms underlying race and gender differences have not been elucidated yet.

Of note, hyperuricemia is associated with increased incidence of stroke as well as increased stroke-related mortality (Kim et al., 2009). In addition, it has been shown that high serum UA level is an independent risk factor for silent brain infarction, especially among women (Heo and Lee, 2010). Taking into account that strokes and silent brain infarcts are associated with AF (Das et al., 2008), it would be reasonable to assume that UA metabolism is involved in stroke pathophysiology, at least in part, through increased AF risk.

\section{THERAPEUTIC IMPLICATIONS}

According to the aforementioned considerations the $\mathrm{XO}$ activity rather than UA should be the primary target (Doehner and Landmesser, 2011) for therapeutic interventions. Taking into account that UA per se may exert prooxidant effects and contribute to atrial remodeling someone could argue that lowering UA levels without interfering in $\mathrm{XO}$ activity may also yield a benefit. However, agents that inhibit renal reabsorption (uricosuric agents) or promote degradation of UA failed to show improvement in endothelial dysfunction or in other clinical variables (Doehner and
Landmesser, 2011). On the other hand, it has been shown that statins, agents with antioxidant properties that may favorably affect atrial remodeling, decrease UA levels, at least in part, by increasing its fractional excretion (Moutzouri et al., 2012).

Allopurinol represents a competitive inhibitor of $\mathrm{XO}$ at low doses and a non-competitive inhibitor at high doses which is in clinical use for the treatment of hyperuricemia (Kelkar et al., 2011). It has been shown that allopurinol improves endothelial dysfunction in a variety of clinical conditions (Kelkar et al., 2011). Notably, recent clinical evidence suggests that allopurinol reduces blood pressure in essential hypertension (Feig et al., 2008), and exerts significant anti-ischemic effects in patients with stable angina (Noman et al., 2010). It should be pointed out that, in contrast to older studies, highdose allopurinol schemes were tested in these studies. In keeping with these findings, a large cohort study indicated that high-dose allopurinol use ( $\geq 300 \mathrm{mg} /$ day) is associated with a lower-risk for cardiovascular events and all-cause mortality compared to lower doses (Wei et al., 2011). No clinical trial to date has examined the effect of allopurinol administration on AF. Only one observational study, published in the abstract form, reported that patients receiving UA lowering agents had decreased AF prevalence without mentioning further details (Kuwabara et al., 2012). Furthermore, it has been reported that high-dose allopurinol may reduce the incidence of complications after coronary bypass surgery, including arrhythmias (Weimert et al., 2003).

Interestingly, in a very recent experimental study using a dog model of atrial tachypacing - induced cardiomyopathy, allopurinol attenuated the reduction of atrial effective refractory period and the duration of AF while suppressed the atrial fibrosis and the reduction endothelial NO synthase protein expression without affecting the left ventricular ejection fraction or the LA diameter (Sakabe et al., 2012). Apart from potential direct effects on atrial remodeling, the aforementioned favorable hemodynamic effects of high-dose allopurinol may provide additional benefit in AF. Finally, there are no data on the cardiovascular effects of the newly released nonpurine XO inhibitor febuxostat. 
Table 1 | Epidemiological studies reporting an association between atrial fibrillation and uric acid levels.

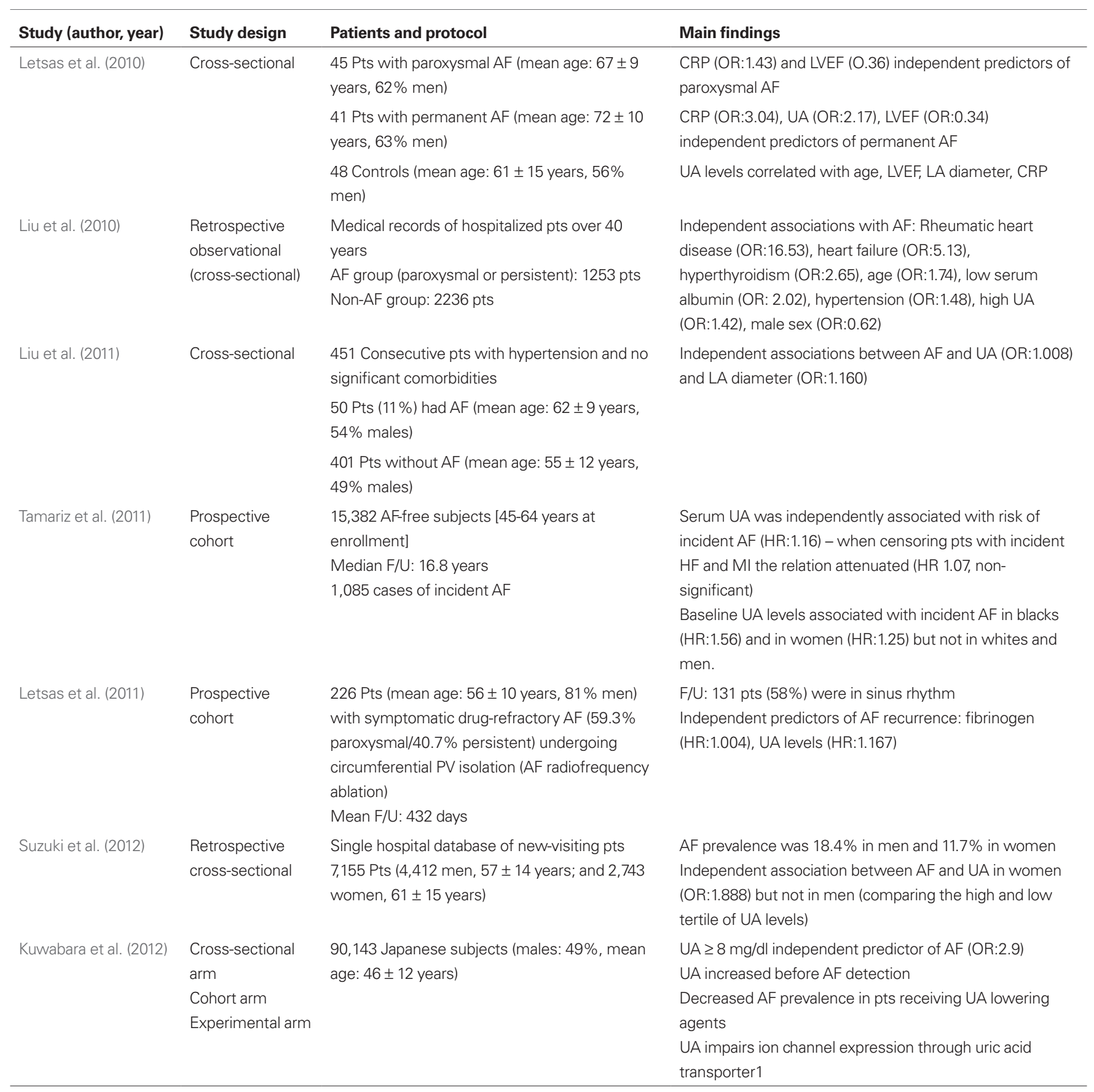

AF, atrial fibrillation; CRP, C-reactive protein; HR, hazard ratio; LVEF, left ventricular ejection fraction; OR, odds ratio; pts, patients; UA, uric acid.

\section{CONCLUSION}

Uric acid appears to be an emerging risk factor for AF. In the aforementioned studies, UA levels have been associated with incident $\mathrm{AF}$ as well as with the $\mathrm{AF}$ burden. However, the exact prognostic role of UA in terms of AF development should be further evaluated by large prospective studies. In addition, gender and race differences should be further investigated. Indeed, agents targeting $\mathrm{XO}$ and UA metabolism represent a promising strategy as an upstream therapy of AF (especially for primary prevention, in high risk individuals) but need to be carefully tested in randomized clinical trials. Finally, the exact value of higher doses of $\mathrm{XO}$ inhibitors such as allopurinol as well as the potential additive value to existing upstream strategies represents a subject of future research.

\section{REFERENCES}

Cai, H., Li, Z., Goette, A., Mera, F., Honeycutt, C., Feterik, K., Wilcox, J. N., Dudley, S. C. Jr., Harrison, D. G., and Langberg, J. J. (2002). Downregulation of endocardial nitric oxide synthase expression and nitric oxide production in atrial fibrillation: potential mechanisms 
for atrial thrombosis and stroke. Circulation 106, 2854-2858.

Chrysohoou, C., Pitsavos, C., Barbetseas, J., Brili, S. Kotroyiannis, I., Papademetriou, L., Metallinos, G., Skoumas, J., Tentolouris, C., and Stefanadis, C. (2008). Serum uric acid levels correlate with left atrial function and systolic right ventricular function in patients with newly diagnosed heart failure: the hellenic heart failure study. Congest. Heart Fail. 14, 229-233.

Das, R. R., Seshadri, S., Beiser, A. S., Kelly-Hayes, M., Au, R., Himali, J. J., Kase, C. S., Benjamin, E. J., Polak, J. F., O’Donnell, C. J., Yoshita, M., D’Agostino, R. B. Sr., DeCarli, C., and Wolf, P.A. (2008). Prevalence and correlates of silent cerebral infarcts in the Framingham offspring study. Stroke 39, 2929-2935.

Dawson, J., and Walters, M. (2006). Uric acid and xanthine oxidase: future therapeutic targets in the prevention of cardiovascular disease? Br. J. Clin. Pharmacol. 62, 633-644.

Doehner, W., and Landmesser, U. (2011). Xanthine oxidase and uric acid in cardiovascular disease: clinical and therapeutic options. Semin. Nephrol.31,433-440.

Dudley, S. C. Jr., Hoch, N. E., McCann, L. A., Honeycutt, C., Diamandopoulos, L., Fukai, T., Harrison, D. G., Dikalov, S. I., and Langberg, J. (2005). Atrial fibrillation increases production of superoxide by the left atrium and left atrial appendage: role of the NADPH and xanthine oxidases. Circulation 112, 1266-1273.

Feig, D. I., Soletsky, B., and Johnson, R. J. (2008). Effect of allopurinol on blood pressure of adolescents with newly diagnosed essential hypertension: a randomized trial. JAMA 300, 924-932.

George, J., and Struthers, A. D. (2008). The role of urate and xanthine oxidase inhibitors in cardiovascular disease. Cardiovasc. Ther. 26, 59-64.

Glantzounis, G. K., Tsimoyiannis, E. C., Kappas, A. M., and Galaris, D. A. (2005). Uric acid and oxidative stress. Curr. Pharm. Des. 11, 4145-4151.

Grum, C. M., Gallagher, K. P., Kirsh, M. M., and Shlafer, M. (1989). Absence of detectable xanthine oxidase in human myocardium. J. Mol. Cell. Cardiol. 21, 263-267.

Hellsten-Westing, Y. (1993). Immunohistochemical localization of xanthine oxidase in human cardiac and skeletal muscle. Histochemistry 100, 215-222.

Heo, S. H., and Lee, S. H. (2010). High levels of serum uric acid are associated with silent brain infarction. J. Neurol. Sci. 297, 6-10.

Hoeper, M. M., Hohlfeld, J. M., and Fabel, H. (1999). Hyperuricaemia in patients with right or left heart failure. Eur. Respir. J. 13, 682-685.

Kelkar, A., Kuo, A., and Frishman, W. H. (2011). Allopurinol as a cardiovascular drug. Cardiol. Rev. 19, 265-271.

Kim, S. Y., Guevara, J. P., Kim, K. M., Choi, H. K., Heitjan, D. F., and Albert, D. A. (2009). Hyperuricemia and risk of stroke: a systematic review and meta-analysis. Arthritis Rheum. 61, 885-892.

Kim, Y. M., Guzik, T. J., Zhang, Y. H., Zhang, M. H., Kattach, H., Ratnatunga, C., Pillai, R., Channon, K. M., and Casadei, B. (2005). A myocardial Nox2 containing $\mathrm{NAD}(\mathrm{P}) \mathrm{H}$ oxidase contributes to oxidative stress in human atrial fibrillation. Circ. Res. 97, 629-636.

Korantzopoulos, P., Kolettis, T. M., Galaris, D., and Goudevenos, J.A. (2007). The role of oxidative stress in the pathogenesis and perpetuation of atrial fibrillation. Int. J. Cardiol. 115, 135-143.

Kuwabara, M., Niwa, K., and Niinuma, H. (2012). Hyperuricemia is an independent risk factor of atrial fibrillation due to electrical remodeling through activation of uric acid transporter [Abstract]. ACC 2012. J. Am. Coll. Cardiol. 59(Suppl. A), Al63.

Landmesser, U., Spiekermann, S., Preuss, C., Sorrentino, S., Fischer, D., Manes, C., Mueller, M., and Drexler, H. (2007). Angiotensin II induces endothelial xanthine oxidase activation: role for endothelial dysfunction in patients with coronary disease. Arterioscler. Thromb. Vasc. Biol. 27, 943-948.

Letsas, K. P., Korantzopoulos, P., Filippatos, G. S., Mihas, C. C., Markou, V., Gavrielatos, G., Efremidis, M., Sideris, A., and Kardaras, F. (2010). Uric acid elevation in atrial fibrillation. Hellenic J. Cardiol. 51, 209-213.

Letsas, K. P., Siklódy, C. H., Korantzopoulos, P., Weber, R., Bürkle, G., Mihas, C. C., Kalusche, D., and Arentz, T. (2011). The impact of body mass index on the efficacy and safety of catheter ablation of atrial fibrillation. Int. J. Cardiol. PMID: 21726910. [Epub ahead of print].

Liu, T., Zhang, X., Korantzopoulos, P., Wang, S., and Li, G. (2011). Uric acid levels and atrial fibrillation in hypertensive patients. Intern. Med. 50, 799-803.

Liu, Y., Liu, H., Dong, L., Chen, J., and Guo, J. (2010). Prevalence of atrial fibrillation in hospitalized patients over 40 years old: ten-year data from the People's Hospital of Peking University. Acta Cardiol. 65, 221-224.

MacGowan, S. W., Regan, M. C., Malone, C., Sharkey, O., Young, L., Gorey, T. F., and Wood, A. E. (1995). Superoxide radical and xanthine oxidoreductase activity in the human heart during cardiac operations. Ann. Thorac. Surg. 60, 1289-1293.

Moutzouri, E., Liberopoulos, E. N., Florentin, M., Liamis, G., and Elisaf, M. S. (2012). Effects of statin monotherapy versus statin plus ezetimibe combination on serum uric acid levels. J. Cardiovasc. Pharmacol. Ther. PMID: 22539817. [Epub ahead of print].

Ndrepepa, G., Braun, S., Haase, H. U., Schulz, S., Ranftl, S., Hadamitzky, M., Mehilli, J., Schömig, A., and Kastrati, A. (2012). Prognostic value of uric acid in patients with acute coronary syndromes. Am. J. Cardiol. 109, 1260-1265.

Negi, S., Sovari, A. A., and Dudley, S. C. Jr. (2010). Atrial fibrillation: the emerging role of inflammation and oxidative stress. Cardiovasc. Hematol. Disord. Drug Targets 10, 262-268.

Noman, A., Ang, D. S., Ogston, S., Lang, C. C., and Struthers, A. D. (2010). Effect of high-dose allopurinol on exercise in patients with chronic stable angina: a randomised, placebo controlled crossover trial. Lancet $375,2161-2167$.

Ruggiero, C., Cherubini, A., Ble, A., Bos, A. J., Maggio, M., Dixit, V. D., Lauretani, F., Bandinelli, S., Senin, U., and Ferrucci, L. (2006). Uric acid and inflammatory markers. Eur. Heart J. 27, 1174-1181.

Sakabe, M., Fujiki, A., Sakamoto, T., Nakatani, Y., Mizumaki, K., and Inoue, H. (2012). Xanthine oxidase inhibition prevents atrial fibrillation in a canine model of atrial pacing-induced left ventricular dysfunction. J. Cardiovasc. Electrophysiol. (in press). doi: 10.1111/j.1540-8167.2012.02356.x

Schotten, U., Verheule, S., Kirchhof, P., and Goette,A. (2011). Pathophysiological mechanisms of atrial fibrillation: a translational appraisal. Physiol. Rev. 91, 265-325.

Shi, Y., Evans, J.E., and Rock, K. L. (2003). Molecular identification of a danger signal that alerts the immune system to dying cells. Nature 425, 516-521.

Suzuki, S., Sagara, K., Otsuka, T., Matsuno, S., Funada, R., Uejima, T., Oikawa, Y., Koike, A., Nagashima, K., Kirigaya, H., Yajima, J., Sawada, H., Aizawa, T., and Yamashita, T. (2012). Gender-specific relationship between serum uric Acid level and atrial fibrillation prevalence. Circ. J. 76, 607-611.

Tamariz, L., Agarwal, S., Soliman, E. Z., Chamberlain, A. M., Prineas, R., Folsom, A. R., Ambrose, M., and Alonso, A. (2011). Association of serum uric acid with incident atrial fibrillation (from the Atherosclerosis Risk In Communities [ARIC] study). Am. J. Cardiol. 2011, 108, 1272-1276.

Van Wagoner, D. R. (2003). Molecular basis of atrial fibrillation: a dream or a reality? J. Cardiovasc. Electrophysiol. 14, 667-669.

Van Wagoner, D. R. (2008). Oxidative stress and inflammation in atrial fibrillation: role in pathogenesis and potential as a therapeutic target. J. Cardiovasc. Pharmacol. 52, 306-313.

Wakili, R., Voigt, N., Kaab, S., Dobrev, D., and Nattel, S. (2011). Recent advances in the molecular pathophysiology of atrial fibrillation. J. Clin. Invest. 121, 2955-2968.

Watanabe, E. (2012). Uric acid and atrial fibrillation cause or other association? Circ. J. 76, 584-585.

Wei, L., Mackenzie, I. S., Chen, Y., Struthers, A. D., and MacDonald, T. M. (2011). Impact of allopurinol use on urate concentration and cardiovascular outcome. Br. J. Clin. Pharmacol. 71, 600-607.

Weimert, N. A., Tanke, W. F., and Sims, J. J. (2003). Allopurinol as a cardioprotectant during coronary artery bypass graft surgery. Ann. Pharmacother. 37, 1708-1711.

Received: 09 April 2012; accepted: 02 May 2012; published online: 24 May 2012.

Citation: Korantzopoulos P, Letsas KP and Liu T (2012) Xanthine oxidase and uric acid in atrial fibrillation. Front. Physio. 3:150. doi: 10.3389/fphys.2012.00150

This article was submitted to Frontiers in Cardiac Electrophysiology, a specialty of Frontiers in Physiology. Copyright (๑) 2012 Korantzopoulos, Letsas and Liu. This is an open-access article distributed under the terms of the Creative Commons Attribution Non Commercial License, which permits non-commercial use, distribution, and reproduction in other forums, provided the original authors and source are credited. 